\title{
PEMBERIAN MASASE DENGAN PERKEMBANGAN USIA 12-24 BULAN DI POSYANDU RT 09 RW 06 KELURAHAN BANYU URIP KECAMATAN SAWAHAN SURABAYA
}

\author{
Siti Nurjanah \\ Fakultas Keperawatan dan Kebidanan \\ Universitas Nahdlatul Ulama Surabaya - Jl Smea 57 Surabaya \\ Email: nungj@unusa.ac.id
}

\begin{abstract}
: the relation in giving massage with the growth of children in age 12-24 months. Children are normally able to walk in age 14 months. However, occasionally some of them could not walk due the massage that is given to them is not appropriate with their age. Based on the study purposed by Purwati in 2010, she found 27 of children under five years, 12 out of them have an indecisive growth, 2 out of them have divergent growth, and 13 out of them have appropriate growth. This present study purposes to get the understanding of the relation in giving massage with the growth of children in age 12-24 months.

The researcher gets the sample in Posyandu RT 09 RW 06 Kelurahan Banyu Urip Kecamatan Sawahan Surabaya. The approach of this study is analysis by cross sectional approach. The population of this study is 45 mothers and their 12-24 months children with the sample is 41 respondents taken by simple random sampling, variable of this study is giving massage and children development with questionnaire instrument and KPSP. The researcher uses statistical test from Rank Spearman with the significant 0.05 .

The result of this study shows that almost a half of children in age 12-24 months (39.1\%) have good massage and (36.6\%) children get an appropriate growth. The result of statistical test of Rank Spearman shows that $(0.00)<(0.05)$, therefore Ho is ignorance. It means that there is a relation in giving massage with the growth of children in age 12-24 months.

Conclusion from this study is the better massage provided the better the child's developmental level. The researcher suggests the mother to be more active in children give massage and find the information about the stimulation of children development, thus, the parents are able to give the appropriate stimulation for their children.
\end{abstract}

\begin{abstract}
Abstrak: Pemberian Masase Dengan Perkembangan Usia 12-24 Bulan Di Posyandu RT 09 Rw 06 Kelurahan Banyu Urip Kecamatan Sawahan Surabaya. Balita usia 14 bulan seharusnya bisa berjalan dengan baik tetapi kenyataannya balita usia 14 bulan belum bisa berdiri karena masase bayi tidak rutin dilakukan. Hasil penelitian Purwati, 2010 di Jawa Timur dari 27 balita, 12 balita perkembangannya meragukan, 2 balita perkembangannya menyimpang dan 13 balita mengalami perkembangan sesuai usia. Tujuan penelitian adalah mengetahui hubungan pemberian masase bayi dengan perkembangan usia 12-24 bulan.

Desain penelitian adalah analitik dengan pendekatan cross sectional. Populasinya adalah seluruh ibu dan balita usia 12-24 bulan sebesar 45 responden dan besar sampel sebesar 41 responden diambil dengan cara simple random sampling dengan variabel pemberian masase dan perkembangan balita. Instrumen yang digunakan adalah kuesioner dan KPSP. Uji statistik yang digunakan adalah Rank Spearman dengan tingkat kemaknaan 0,05.

Hasil penelitian adalah dari 41 balita usia 12-24 bulan, hampir setengahnya $(39,1 \%)$ mendapatkan massage rutin dan sebanyak $36,6 \%$ balita mengalami perkembangan yang sesuai. Hasil uji statistik Rank Spearman diperoleh $\rho(0,00)<\alpha(0,05)$ sehingga Ho ditolak, yang berarti ada hubungan pemberian masase dengan perkembangan balita usia 12-24 bulan.

Simpulan penelitian ini adalah semakin rutin masase yang diberikan pada balita maka semakin baik pula tingkat perkembangan anak. Ibu balita disarankan aktif sering untuk memberikan masase pada balita dan memantau perkembangan anak sehingga balita dapat mencapai perkembangan yang optimal dan sesuai dengan usia.
\end{abstract}

Kata kunci: Massage, Perkembangan. 


\section{PENDAHULUAN}

Manusia dalam kehidupannya mengalami pertumbuhan dan perkembangan. Keduanya mempunyai masa yang sangat menentukan, yaitu masa balita, karena pada masa ini pertumbuhan dasar akan mempengaruhi dan menentukan perkembangan anak selanjutnya, seperti perkembangan bahasa, kesadaran sosial, dan perkembangan motorik anak. Perkembangan anak terdapat masa kritis, dimana diperlukan suatu rangsangan atau stimulasi yang berguna agar potensi anak berkembang (Adriana, 2011).

Balita usia 14 bulan seharusnya sudah bisa berjalan dengan baik tapi pada kenyataannya balita usia 14 bulan masih belum bisa berdiri hal ini dikarenakan orang tua masih memberikan anak mainan bunyi-bunyian yang seharusnya untuk usia perkembangan balita usia 14 bulan adalah orang tua membelikan mainan yang berwarna terang dan dapat bergerak misal mobil-mobilan agar anak tertarik dan termotivasi untuk berjalan. Selain itu balita usia 21 bulan dan 23 bulan belum bisa mengucapkan kata "mama papa" dengan baik, seharusnya orang tua dapat merangsang perkembangan bahasa dan bicara anak dengan sering membacakan anak buku cerita agar perkembangan bahasa dan bicara anak menjadi lebih optimal.

Hasil penelitian Purwati (2010) di wilayah Gresik, Jawa timur didapatkan hasil bahwa dari 27 balita sebanyak 12 balita perkembangannya meragukan, 2 balita mengalami perkembangan yang menyimpang dan 13 balita mengalami perkembangan sesuai usia.

Pijat atau masase bayi merupakan salah satu cara yang menyenangkan yang akan membuat perasaan nyaman bagi bayi. Karena pijatan lembut akan membantu meringankan ketegangan otot sehingga bayi menjadi tenang dan tidur (Pranoto, 2009). Peneliti dari Warwick medical school dan institute of education dari University of Warwick, meneliti 9 gerakan pijat bayi yang di terapkan kepada 598 bayi usia di bawah 6 bulan. Hasil penelitian tersebut salah satunya di sebutkan bahwa pijat bayi dapat mempengaruhi keluarnya hormone tidur melatonin, dengan hormone tersebut bayi dapat memiliki pola tidur yang teratur sehingga perkembangan bayi dapat di capai dengan optimal.

Perkembangan dapat dipengaruhi oleh beberapa faktor yaitu faktor internal meliputi bangsa, umur, jenis kelamin dan genetik, sedangkan faktor eksternal dibagi menjadi 3 yaitu prenatal (gizi, toksin, radiasi, endokrin, infeksi, kelainan imunologi), natal (trauma kepala, asfiksia) dan postnatal (lingkungan pengasuh, gizi, status sosial ekonomi, status kesehatan dan stimulasi) (Narendra, 2002). Stimulasi yang kurang akan mempengaruhi pada perkembangan anak seperti gangguan bicara, misalnya anak yang kurang diajak bicara dan kurang mendapat stimulus dalam hal bicara akan mengakibatkan kurang dalam kemampuan bahasa, terlambatnya motorik kasar seperti anak yang kurang distimulus untuk berjalan akan terlambat dalam hal motorik kasar yaitu terlambat berjalan, terlambat motorik halus serta sosial. Perkembangan personal sosial sangat dipengaruhi oleh lingkungan dan interaksi antara anak dan orang tuanya, lingkungan yang tidak mendukung akan menghambat perkembangan anak (Adriana, 2011). Anak yang mendapatkan stimulasi yang terarah dan teratur akan lebih cepat berkembang dibandingkan anak yang kurang atau tidak mendapat stimulasi (Soetjiningsih, 2002) .

Perkembangan balita sangat penting, untuk itu perlu upaya untuk memotivasi masyarakat terutama ibu atau pengasuh untuk memberikan stimulasi sejak dini pada balita dengan memberikan penyuluhan dan melatih skill dalam memberikan stimulasi sehingga para ibu atau pengasuh dapat memberikan atau mendemonstrasikan cara memberi stimulasi pada balita sesuai dengan tahap perkembangannya. Pemberian stimulasi yang teratur dan terus-menerus akan menciptakan anak yang cerdas, bertumbuh kembang dengan optimal, mandiri, memiliki emosi yang stabil serta mudah beradaptasi.

Berdasarkan uraian di atas, maka peneliti tertarik untuk meneliti tentang "hubungan antara pemberian massage dengan perkembangan usia 12-24 bulan di posyandu RT 09 RW 06 Kelurahan Banyu Urip Kecamatan Sawahan Surabaya". 


\section{METODE PENELITIAN}

Rancangan atau desain penelitian yang digunakan adalah analitik observational. Populasi dalam penelitian ini adalah seluruh ibu atau pengasuh beserta balita usia 12-24 bulan RT 09 RW 06 Kelurahan Banyu Urip Kecamatan Sawahan Surabaya dengan jumlah 43 ibu dan anaknya pada bulan Juli 2015. Sampel dalam penelitian ini adalah sebagian ibu dan pengasuh beserta balita yang berada di RT 09 RW 06 Kelurahan Banyu Urip Surabaya. Besar Sampel adalah 41 responden. Cara pengambilan sampel menggunakan simple random sampling. Istrumen penelitian berupa lembar observasi KPSP untuk perkembangannya.

\section{HASIL \& PEMBAHASAN}

\section{a. Hasil}

Pengumpulan data umum berisi karakteristik responden yang meliputi pendidikan, urutan lahir, jenis kelamin ibu atau pengasuh balita di RT 09 RW 06 Kelurahan Banyu Urip Surabaya.

a. Pendidikan

Tabel 1 Distribusi pendidikan responden

\begin{tabular}{ccc}
\hline Pendidikan & Frekuensi & $\begin{array}{c}\text { Presentase } \\
(\%)\end{array}$ \\
\hline Dasar & 3 & 7,3 \\
Menengah & 13 & 31,7 \\
Tinggi & 25 & 61 \\
\hline Jumlah & 41 & 100 \\
\hline
\end{tabular}

Sumber : Data Primer September 2015

Tabel 1 menunjukkan bahwa dari 41 responden sebagian besar (61\%) berpendidikan tinggi

b. Urutan Lahir

Tabel 2 Distribusi urutan lahir responden

\begin{tabular}{ccc}
\hline Urutan Lahir & Frekuensi & $\begin{array}{c}\text { Presentase } \\
(\%)\end{array}$ \\
\hline Primipara & 12 & 29,27 \\
Multipara & 29 & 70,73 \\
\hline Jumlah & 41 & 100 \\
\hline
\end{tabular}

Sumber : Data Primer September 2015

Tabel 2 menunjukkan bahwa dari 41 responden sebagian besar $(70,73 \%)$ multipara c. Jenis Kelamin

Tabel 3 Distribusi jenis kelamin responden

\begin{tabular}{ccc}
\hline $\begin{array}{c}\text { Jenis } \\
\text { Kelamin }\end{array}$ & Frekuensi & $\begin{array}{c}\text { Presentase } \\
(\%)\end{array}$ \\
\hline Laki-laki & 19 & 46,34 \\
Perempuan & 22 & 53,66 \\
\hline Jumlah & 41 & 100 \\
\hline
\end{tabular}

Sumber : Data Primer September 2015

Tabel 3 menunjukkan bahwa dari 41 responden sebagian besar $(53,66 \%)$ berjenis kelamin perempuan.

Data khusus meliputi pemberian masase dan perkembangan balita.

a. Karakteristik responden berdasarkan Pemberian Masase

Tabel 4 Karakteristik responden berdasarkan pemberian masase

\begin{tabular}{ccc}
\hline Masase & Frekuensi & $\begin{array}{c}\text { Presentase } \\
(\%)\end{array}$ \\
\hline Baik & 16 & 39,1 \\
Cukup & 14 & 34,1 \\
Kurang & 11 & 26,8 \\
\hline Jumlah & 41 & 100 \\
\hline \multicolumn{2}{l}{ Sumber : Data Primer September 2015}
\end{tabular}

Tabel 4 menunjukkan bahwa dari 41 responden hampir setengah $(39,1 \%)$ mendapatkan masase baik.

b. Karaktertistik responden berdasarkan perkembangan balita

Tabel 5 Karaktertistik responden berdasarkan perkembangan balita Perkembangan Frekuensi Presentase

\begin{tabular}{ccc} 
& & $(\%)$ \\
\hline Sesuai & 15 & 36,6 \\
Meragukan & 14 & 34,1 \\
Menyimpang & 12 & 29,3 \\
\hline Jumlah & 41 & 100
\end{tabular}

Sumber : Data Primer September 2015

Tabel 5 menunjukkan bahwa dari 41 responden hampir setengah (36,6\%) mempunyai perkembangan sesuai.

Tabel 6 Tabulasi silang hubungan antara pemberian masase dengan perkembangan balita usia 12-24 bulan di RT 09 RW 06 
Kelurahan banyu Urip Kecamatan Sawahan Surabaya

\begin{tabular}{|c|c|c|c|c|}
\hline \multirow{2}{*}{$\begin{array}{c}\text { Masase } \\
\text { pada } \\
\text { balita }\end{array}$} & \multicolumn{3}{|c|}{ Perkembangan } & \multirow{2}{*}{$\begin{array}{c}\text { Juml } \\
\text { ah } \\
\mathrm{N}(\%)\end{array}$} \\
\hline & $\begin{array}{l}\text { Sesuai } \\
\mathrm{N}(\%)\end{array}$ & $\begin{array}{c}\text { Meragu } \\
\text { kan } \\
\mathrm{N}(\%)\end{array}$ & $\begin{array}{c}\text { Menyim } \\
\text { pang } \\
\mathrm{N}(\%)\end{array}$ & \\
\hline Baik & $\begin{array}{c}13 \\
(81,3)\end{array}$ & $2(12,5)$ & $1(6,3)$ & $\begin{array}{c}16 \\
(100)\end{array}$ \\
\hline Cukup & $\begin{array}{c}2 \\
(14,3)\end{array}$ & $\begin{array}{c}11 \\
(78,6)\end{array}$ & $1(7,14)$ & $\begin{array}{c}14 \\
(100)\end{array}$ \\
\hline Kurang & $0(0)$ & $1(9,1)$ & $\begin{array}{c}10 \\
(90,9)\end{array}$ & $\begin{array}{c}11 \\
(100)\end{array}$ \\
\hline Jumlah & 15 & 14 & 12 & 41 \\
\hline
\end{tabular}

Sumber : Data Primer September 2015

\section{b. Pembahasan}

\section{a. Pemberian Masase}

Hasil data pada tabel 4 menunjukan bahwa dari 41 balita usia 12-24 bulan hampir setengahnya $(39,1 \%)$ mendapatkan masase baik. Ibu yang telah memberikan masase yang baik untuk balitanya menunjukan bahwa ibu telah menyadari akan pentingnya massage untuk perkembangan balitanya karena peran aktif orang tua untuk memberikan masase sangat penting. Masase yang diberikan oleh orang tua juga dapat diberikan dengan cara anak diajak sambil bermain dengan menggunakan permainan edukatif yang juga dapat merangsang perkembangan balita. Masase yang kurang tepat dapat menyebabkan anak menjadi tidak nyaman. Menurut pendapat Awi Muliadi (2005) masase yang baik adalah masase yang diberikan sesuai dengan aturan yang benar sesuai dengan tahap perkembangan anak dan sebaiknya dilakukan oleh orang-orang terdekat anak terutama ibu.

Salah satu faktor yang mempengaruhi pemberian masase adalah tingkat pendidikan ibu. Hasil tabel 1 menunjukan bahwa dari 41 ibu yang memiliki balita 12-24 bulan hampir setengahnya $(61 \%)$ berpendidikan tinggi. Pendidikan orang tua yang cukup tinggi ini sangat mempengaruhi pemberian masase karena orang tua yang memiliki pendidikan tinggi pada umumnya lebih mudah menerima dan memahami informasi baru dari pada orang tua yang memiliki pendidikan rendah. Pengetahuan tentang masase ini tidak hanya diperoleh dari pendidikan formal tetapi juga dapat diperoleh dari pendidikan non formal seperti dari penyuluhan kesehatan yang telah diberikan posyandu tentang gizi, perkembangan dan imunisasi, media cetak, media elektronik dan dari pengalaman diri sendiri maupun orang lain. (Sekartini, 2013).

Hasil tabel 2 berdasarkan urutan lahir dari 41 responden sebagian besar $(70,73 \%)$ multipara. Balita yang memiliki urutan lahir bukan dari anak pertama akan mendapatkan massage yang baik dari orang tua maupun pengasuh hal ini dapat terjadi karena orang tua telah memiliki pengalaman tentang cara memberikan massage kepada anak sehingga pemahaman dan penerapan stimulasi akan lebih mudah. Orang tua yang mempunyai pengalaman sebelumnya dalam merawat anak akan lebih siap menjalankan peran pengasuhan dan pemberian stimulasi yang terarah serta lebih mampu mengamati tandatanda pertumbuhan dan perkembangan anak yang optimal (Hasanah, 2012).

\section{b. Perkembangan Balita}

Hasil data pada tabel 5 menunjukan bahwa dari 41 balita usia 12-24 bulan hampir setengahnya $(36,6 \%)$ mengalami perkembangan yang sesuai dengan tahap perkembangannya. Balita yang memiliki perkembangan yang sesuai berarti telah mendapatkan perhatian akan kebutuhan perkembangan dari orang tua ataupun pengasuh. Setiap orang tua pasti menginginkan anaknya berkembang secara optimal sehingga orang tua terus memberikan rangsangan kepada balitanya untuk mengoptimalkan setiap aspek perkembangan anak karena peran aktif orang tua sangat diperlukan dalam mewujudkan perkembangan anak yang optimal. Perkembangan anak yang optimal dimasa balita akan mempengaruhi perkembangan anak selanjutnya. Menurut Feiby (2010) Peranan orang tua terutama ibu sangat bermanfaat bagi proses perkembangan anak secara keseluruhan karena orang tua dapat segera mengenali kelainan proses perkembangan anaknya dan sedini mungkin untuk memberikan stimulasi pada tumbuh kembang anak secara menyeluruh dalam aspek motorik, bahasa dan sosial.

Hasil tabel 3 menunjukan bahwa dari 41 responden balita sebagian besar $(53,66 \%)$ memiliki jenis kelamin perempuan. Pembawaan lahir dapat berupa fisik, 
mental dan jenis kelamin individu. Salah satu faktor yang mempengaruhi perkembangan adalah jenis kelamin dimana anak perempuan akan mengalami percepatan perkembangan sebelum pubertas tetapi setelah puburtas perkembangan anak laki-laki akan lebih cepat dari pada perempuan sehingga menyebabkan perkembangan balita perempuan akan lebih cepat berkembang. Menurut Narendra (2002) Tidak dapat dipungkiri bahwa jenis kelamin akan mempengaruhi perkembangan anak baik secara fisik maupun mentalnya. Sebelum melewati masa pubertas anak perempuan akan mengalami perkembangan yang lebih cepat dari pada laki-laki.

\section{c. Hubungan Antara Pemberian Masase dengan Perkembangan Balita}

Hasil uji Rank Spearman dengan didapatkan hasil $\rho(0,00)<\alpha(0,05)$, maka Ho ditolak yang berarti ada hubungan pemberian masase dengan perkembangan balita usia 12-24 bulan.

Hasil pada tabel 4 menunjukan bahwa dari 11 balita usia 12-24 bulan yang kurang mendapat masase, hampir seluruhnya mengalami perkembangan yang mungkin ada penyimpangan $(90,9 \%)$. Faktor yang mempengaruhi perkembangan salah satunya adalah masase. Pemberian masase yang baik dan terus menerus dapat membantu balita dalam pencapaian perkembangan yang optimal sesuai dengan tahap perkembangannya. Sebaliknya jika orang tua tidak memberikan masase yang sesuai dengan tahapan perkembangan anak akan mengakibatkan perkembangan anak menjadi kurang optimal. Kurangnya massage yang diberikan pada balita dapat disebabkan juga oleh kurangnya pengetahuan orang tua tentang cara pemberian massage balita serta kurangnya pengalaman orang tua dalam pemberian masase. Orang tua yang mempunyai pengalaman sebelumnya dalam merawat anak akan lebih siap menjalankan peran pengasuhan dan pemberian masase yang terarah serta lebih mampu mengamati tanda-tanda pertumbuhan dan perkembangan anak yang optimal. Menurut Sekartini (2013) Perkembangan yang dialami balita akan sesuai dengan pengalaman sensorik yang diterimanya sehingga jika masase yang diberikan cukup atau kurang akan mempengaruhi perkembangan balita.

Hasil tabel 5.6 juga dapat diketahui bahwa dari 14 anak yang mendapat masase cukup hampir seluruhnya mengalami perkembangan yang meragukan $(78,6 \%)$, sedangkan yang mengalami perkembangan sesuai sebanyak $(14,3 \%)$ dan mungkin ada penyimpangan sebanyak $(7,14 \%)$. Anak membutuhkan masase sejak dini terhadap perkembangan otaknya, karena semakin sering otak menerima stimulus maka semakin sering pula kemampuan itu diasah hingga mencapai tahap mahir atau piawai. Hal ini menyebabkan jika masase yang diberikan pada balita belum optimal mengakibatkan perkembangan balita juga tidak optimal.

Tabel 5 juga menunjukan bahwa dari 16 responden yang mendapat masase baik hampir seluruhnya $(81,3 \%)$ mengalami perkembangan yang sesuai dengan usianya, sebanyak $12,5 \%$ mengalami perkembangan yang meragukan dan $6,3 \%$ mengalami perkembangan yang kemungkinan ada penyimpangan. Masase merupakan salah satu faktor penting yang mempengaruhi perkembangan. Balita yang setiap hari diberi masase yang baik akan memperoleh perkembangan yang sesuai. Hal ini sependapat dengan Soetjiningsih, (2012) anak yang mendapatkan masase yang terarah dan teratur akan lebih cepat berkembang dibandingkan anak yang kurang atau tidak mendapat masase.

\section{KESIMPULAN}

Simpulan dari hasil penelitian ini adalah:

1. Balita usia 12-24 bulan di Posyandu RT 09 RW 06 Kelurahan Banyu Urip Kecamatan Sawahan Surabaya hampir setengahnya mendapatkan massage yang baik.

2. Balita usia 12-24 bulan di Posyandu RT 09 RW 06 Kelurahan Banyu Urip Kecamatan Sawahan Surabaya hampir setengahnya mengalami perkembangan yang sesuai dengan tahap perkembangannya.

3. Ada hubungan antara pemberian massage dengan perkembangan balita usia 12-24 bulan di Posyandu RT 09 
RW 06 Kelurahan Banyu Urip Kecamatan Sawahan Surabaya

\section{SARAN}

1. Bagi institusi pendidikan

Disarankan institusi pendidikan dapat memanfaatkan dan menjadikan referensi sebagai bahan pertimbangan untuk penelitian selanjutnya tentang masase terhadap perkembangan balita.

\section{Bagi tempat penelitian}

Diharapkan bagi profesi atau petugas kesehatan khususnya kader posyandu dapat memberikan penyuluhan secara langsung pada masyarakat terutama ibu pengasuh sehingga dapat meningkatkan pemberian massage pada balita untuk mencapai perkembangan yang optimal.

3. Bagi responden

Masase sangat mempengaruhi perkembangan pada balita, oleh karena itu ibu diharapkan untuk aktif mengikuti penyuluhan dan mencari informasi tentang masase sehingga dapat memberikan masase yang sesuai dengan tahap perkembangan bayinya secara berkesinambungan.

\section{DAFTAR PUSTAKA}

Adriana, Dian. (2011). Tumbuh Kembang dan Terapi bermain pada anak. Jakarta: Salemba Medika.

Arikunto,S. (2002). Prosedur Penelitian Suatu Pendekatan Praktik, Edisi Revisi v. Jakarta: Rineka Cipta.

DepKes RI, (2005). Pedoman Deteksi Kelainan dan Stimulasi Dini Tumbuh Kembang Balita. Jakarta.

DepKes RI, (2006). Instrumen Deteksi Dini Penyimpangan Perkembangan pada Balita dan Anak Prasekolah. Jakarta:

DepKes RI, (2007). Petunjuk Pelaksanaan Deteksi Tumbuh Kembang Balita Bagi Petugas Puskesmas. Jakarata

DepKes RI, (2009). Pedoman Pembinaan Kesehatan Anak Didik Taman Kanak-kanak. Jakarta.

Feiby. (2010). "Peran aktif orang tua terhadap perkembangan anak". www. Parents-babygrowth.com. Artikel diakses tanggal 30 juni 2015. Jam 07.25 WIB.
Hasanah, Tita. (2012) "Ilmu Mengasuh Anak: Sebuah Upaya Memperbaiki Kualitas Bangsa". http://www.academia.edu/534319 2/Pengasuhan_Anak. Artikel diakses tangga 03 Juli 2015 jam 14.10 .

Hidayat (2006). "Faktor-faktor Perkembangan Balita". www.Pdf. Jptpunimus-gdldimasajila. Artikel diakses tanggal 30 Juni 2015. Jam 08.10 WIB.

Indiasari. (2012). "Cara menstimulasi balita sesuai dengan tumbuh kembang anak". http://jurnalbidandiah.com/stimul asi-berdasarkan-tahapan. html. Artikel diakses tanggal 17 Agustus 2015, Jam 12.10 WIB.

Mansur, Herawati (2009) Psikologi ibu dan anak untuk Kebidanan. Jakarta, Salemba Medika.

Narendra, Moersintowarti dkk, (2002). Tumbuh Kembang Anak dan Remaja. Jakarta: Sagung Seto

Notoatmodjo. (2002). Metodelogi Penelitian Kesehatan. Jakarta: Rineka Cipta.

Nursalam. (2013). Metodelogi Penelitian Ilmu Keperawatan. Jakarta: Salemba Medika.

Nursalam. (2003). Konsep Dan Penerapan Metodologi Penelitian Ilmu Keperawatan. Jakarta: Salemba Medika

Purnomo, windhu. (2012). Pengantar Biostatistika. Surabaya:

Purwati. (2010). "Jurnal Perkembangan Balita". http//www.unimus.com /JurnalPerkembangan-Balita.

Artikel diakses tanggal 17 April 2015, Jam 10.20 WIB.

Sekartini, (2013). "Massage Perkembangan otak balita". http: catchcoalition.ca/trellis/learning_a bout_the_brain. Artikel diakses tanggal 1 Juli 2014. Jam 07.05 WIB.

Srihartini. (2013). "Pemberian Massage balita". http://digilib.unimus.ac.id /files/disk1/131/jtptunimus-gdlsrihartini-6528-3-bab2_sk-i.pdf. Artikel diakses tanggal 18 April 2015 Jam 11. 15 WIB.

Soetjiningsih. (2002). Tumbuh Kembang Anak. Jakarta: EGC 